\title{
RICYDE. Revista Internacional de Ciencias del Deporte
} doi:10.5232/ricyde

Rev. int. cienc. deporte

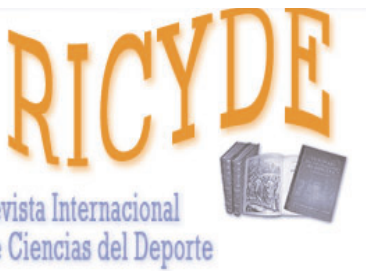

RICYDE. Revista internacional de ciencias del deporte VOLUMEN XI - AÑO XI

Páginas:33-47 ISSN:1885-3137

\section{Motor Skill Learning in Groups: Some Proposals for Applying Implicit Learning and Self-Controlled Feedback Aprendizaje de habilidades/destrezas motoras en grupos: Propuestas para la Aplicación de Aprendizaje Implícito, autocontrolado y retroalimentado}

\author{
John van der Kamp 1,2,3, Joop Duivenvoorden ${ }^{2}$, Marjan Kok ${ }^{1}$ \& Ivo van Hilvoorde ${ }^{1,2}$
}

1.Research Institute MOVE Amsterdam, Faculty of Human Movement Sciences, VU University Amsterdam, The Netherlands 2.Research Centre for Exercise, School and Sport, Windesheim University of Applied Sciences, Zwolle, The Netherlands 3.Institute of Human Performance, University of Hong Kong, Hong Kong SAR, China

\begin{abstract}
Contrary to researchers' current focus on individual motor skill learning, in institutional settings such as physical education and sports motor skill learning is often taught in groups. In these settings, there is not only the interaction between teacher and learner (analogous to research), but also the many interactions between the learners in the group. In this paper, we discuss the pitfalls of applying research findings without taking into account the different dynamics that the interactions between group members bring about. To this end, we especially discuss implicit motor learning and self-controlled feedback, as these have recently been hailed as being particularly effective for increasing motor skill and self-efficacy. Proposals are provided to adopt these methods for motor skill learning in groups. This is not only relevant for practitioners in physical education and sports, but also establishes an agenda for research.
\end{abstract}

Key words: motor learning; group dynamics; physical education; children; implicit learning, selfcontrolled feedback.

\section{Resumen}

A diferencia del enfoque actual de los investigadores sobre aprendizaje de habilidades motrices en contextos institucionales tales como la educación físca y los deportes, el aprendizaje motor se enseña frecuentemente en grupos. En estos contextos no solo hay interacción entre el profesor y el alumno (como en el caso de la investigación), sino que también se producen numerosas interacciones entre los alumnos en el seno del grupo. En este artículo se discuten las dificultades en la aplicación de los resultados de estas investigaciones cuando no se tienen en cuenta las diferentes dinámicas que surgen entre los miembros del grupo. Con este fin, expresamente centramos la atención en el aprendizaje motor implícito y el feedback autorregulado, ya que éste ha sido destacado por ser especialmente eficaz para el aumento de las habilidad motriz y la percepción de autoeficacia. Se ofrecen propuestas para la adopción de estos métodos para el aprendizaje de habilidades motrices en grupo. Esto no solo es relevante para los profesionales de la educación física y el deporte, sino que sirve para establecer una nueva línea de investigación.

Palabras clave: aprendizaje motor; dinámica grupa; educación física; niños; aprendizaje implícito; feedback autorregulado. 


\section{Introduction}

A large chunk of deliberate motor skill learning in childhood takes part in institutional settings such as physical education lessons at schools and training at sport clubs. Crucially, in these settings motor skill learning is taught in groups. Instructions and feedback of the teacher and coach are typically directed to the group of children as a whole, involving benchmark examples and tackling exemplary errors. Instructions or feedback tailored to the needs of the individual child (or a subgroup of children) are less ubiquitous and possibly somewhat cursory. By contrast, research into motor skill learning -and to a lesser extent, theory- predominantly involves individual motor skill learning. By and large, experimental studies in the context of current debates on motor skill learning (e.g., on the role of declarative knowledge, attention focus, variability, feedback frequency and scheduling, and so on) involve researchers that deal with a single participant at the time. Consequently, it is pertinent to establish the degree to which the findings and derived theoretical conceptions can be applied to motor skill learning in groups. Accordingly, the aim of the current paper is to evaluate the viability of recent research and theories on motor skill learning with regard to motor skill learning in groups, particularly groups of children. We will do so in the context of two pivotal discussions in motor skill learning, namely those that centre on i) the purported advantages of implicit learning (i.e., the degree to which the built up of declarative knowledge is mandatory for motor skill learning), and ii) the supposed advantage of selfcontrolled feedback (i.e., the degree to which learners can themselves decide when and how often they receive feedback).

\section{Implicit motor learning}

In recent years, researchers have proposed and developed many new methods for teaching motor skills. In this regard, implicit motor learning may be one of the most conspicuous. An important issue for teachers is to what degree and when implicit learning can be incorporated in physical education classes, where motor skill learning usually takes place in groups. To address this issue, it is pertinent to first provide a clear understanding of what implicit learning is and how it differs from the more traditional explicit learning methods.

\section{Implicit and explicit motor learning}

With explicit motor learning, students initially learn a new motor skill by acquiring declarative knowledge about the manner in which to perform the to-be-learned skill (e.g., Anderson, 1982; Fitts \& Posner, 1967). In physical education, but the same is bound to be true in sports and rehabilitation, this usually involves a teacher prescribing and/or explicating how to optimally perform the skill. In implicit motor learning, by contrast, motor skill learning occurs without the concomitant accumulation of declarative knowledge. Students are not instructed about and may not even deliberately seek to change the way they are moving. This does not imply, however, that implicit learning is merely learning without instructions or feedback -a common misunderstanding. To the contrary, implicit learning requires a deliberate effort to curtail the involvement of working memory, because working memory plays a crucial role in generating and applying declarative knowledge (Berry \& Broadbent, 1988). In fact, Rich Masters already demonstrated this in his 1992 landmark study. He compared three groups of participants learning a golf putting skill. Participants in the explicit group received a set of specific instructions, extracted from reputable coaching sources, about how to best putt a golf ball. The participants in the implicit group received no such instructions, but carried out a random letter generation task while they were putting. The simultaneous letter generation task burdens working memory so that it cannot be used to accrue declarative knowledge about the perfect putt. Finally, participants in the control group 
did not receive the instructions, nor were they required to carry out the secondary task. They were simply told to improve putting performance as much as possible. After five sessions of 100 golf putts, the participants wrote down all the aspects of the golf putt they became aware of and which they felt important for a successful putt. The number of rules the participants reported served as the prime measure for the amount of declarative knowledge accrued during learning; it is the key variable for distinguishing implicit and explicit learning. Masters (1992) found that -as he anticipated- the implicit group's pool of declarative knowledge was trivial and unmistakably smaller than that of the participants in the explicit group. Importantly, however, also the control group had accumulated a considerable amount of rules: less than the explicit group, but significantly more than the implicit group. That is, although they were not given any instructions, the participants in the control group could freely focus attention toward their putting and discover on their own how to improve golf putting. The accompanying accumulation of declarative knowledge indicates that this type of discovery learning is a form of explicit learning. Consequently, to promote implicit learning, it is pertinent to actively prevent the learner from consciously acquiring skill-specific knowledge. Merely stop providing instructions and/or feedback will not automatically result in implicit learning (see also Steenbergen, Van der Kamp, Verneau, Jongbloed-Pereboom \& Masters, 2010). Masters (1992) further showed that a crucial benefit following implicit learning is that it results in more stable performance in the face of psychological pressure. The threat of being evaluated and to lose money resulted in significant decreases in golf putting performance after explicit learning or discovery learning (i.e., the control group), but not after implicit learning -if anything, the latter group increased performance (Masters, 1992; see also Hardy, Mullen \& Jones, 1996; Mullen, Hardy \& Oldham, 2007). Similar performance advantages of implicit learning have been demonstrated under physiological fatigue (Masters, Poolton, \& Maxwell, 2008; Poolton, Masters, \& Maxwell, 2007). Moreover, since implicit motor learning is less reliant on working memory, it is especially advantageous to individuals with poor working memory functioning (Janascek \& Nemeth, 2013). However, a potential downside of implicit learning is that the use of concurrent secondary tasks for hindering that declarative knowledge is acquired (i.e., by loading working memory) may slow down the rate of learning relative to explicit and discovery learning. Hence, there have been continuing (and successful) efforts since to develop methods of implicit learning other than using concurrent secondary tasks that do not adversely affect the rate of learning. We will discuss these methods (e.g., analogy learning, errorless or errorminimizing learning, learning with an external focus of attention) below.

Firstly, however, we consider why physical education teachers would bother at all about implicit learning. Surely, preventing students from break down of performance under psychological pressure (as in choking) or physiological fatigue are usually not primary goals of physical education. Instead, improving motor skills per se and increasing a student's selfefficacy (i.e., the extent of a student's belief in her/his own ability to solve a motor task) are often considered much more worthy goals (Brouwer, Houthoff, Massink, Mooij, Mossel, \& Swinkels, 2012; Hellision, 1984). In this respect, recent work by Capio and colleagues, which examined motor skill learning in children, is pertinent (for a recent overview, see Masters, van der Kamp \& Capio, 2013). Capio, Poolton, Sit, Holmstrom, and Masters (2013), for example, reported that primary school children, who practiced throwing a beanbag to a target, showed larger gains in throwing form with implicit than explicit learning. Similarly, throwing accuracy also increased to a greater extent with implicit learning, but only for children with lower motor ability. These findings fit with theoretical predictions that implicit learning is especially advantageous for children, because it is much less dependent on developing cognitive abilities such as working memory, which is critical to generating, testing and 
applying declarative knowledge on how to perform a motor skill (e.g., Reber, 1992; Masters et al., 2013). Accordingly, implicit learning was also associated with greater improvement in throwing performance in intellectually disabled children, particularly with respect to movement form (Capio, Poolton, Sit, Equia \& Masters, 2012). Intriguingly, the implicit motor learning intervention also increased the frequency of throwing actions during free play in the classroom relative to explicit learning (Capio et al., 2013). This might suggest that after implicit learning not only children's motor skill improved, but also their self-efficacy was enhanced. Children are more likely to engage in activities that they feel competent in (e.g., Harter, 1987; cf. Capio et al., 2012, p. 304). Obviously, we are in a dire need for studies that further substantiate these observations and conjectures, not in the least because Capio et al. did not directly assess children's self-efficacy.

\section{Methods for implicit motor learning}

Explicit motor learning methods aim to develop an acute awareness of the many details of the desired movement form on the side of the learner by providing her or him comprehensive instructions and feedback. Methods for implicit motor learning, by contrast, attempt to minimize the amount of declarative knowledge that a learner accumulates during practice. Several of these methods to produce implicit motor learning have been validated. The first is to use analogies that only convey the global characteristic of the desired movement form. For instance, Liao and Masters (2001) instructed participants who were learning to hit a table tennis forehand with top spin, to "pretend drawing a right-angled triangle with the bat and strike the ball while bringing the bat up to the hypotenuse of the triangle', or Lam, Maxwell and Masters (2009) told participants to finish a basketball shot as if 'trying to put cookies into a cookie jar on a high shelf'. Analogy learning encourages the correct movement form by reducing the many separate movements that make up the action into one biomechanical metaphor (Lam et al., 2009). Analogy learning results in similar low amount of declarative knowledge as implicit learning with concurrent secondary tasks that load working memory, and hence, much less than after explicit learning (Liao \& Masters, 2001; see also Lam et al., 2009). A second method for implicit motor learning is errorless or error-minimizing learning. Error-minimizing learning aims at lessening self-evaluation by constraining the environment such that the likelihood for errors is very low. Making hardly any errors hampers hypothesis testing about how movement performance can be optimized, and hence, little or no declarative knowledge will be accumulated. Error-minimizing learning has been successfully used to induce implicit motor learning in, for instance, golf putting and ball throwing, with the participants initially practicing at close distance to the hole or target but with the distance slowly being increased to enhance learning (Maxwell, Masters, Kerr \& Weedon, 2001; Capio et al., 2013). A third, more contentious, method for implicit learning is learning with an external focus of attention. Here, instructions are provided that direct a learner's attention to the effect or outcome of the action in the environment, instead of on how the action is best executed (i.e., internal focus of attention). In an early study, for instance, Wulf and colleagues required participants to make ski-slalom-like actions on a small moving platform (Wulf, Höß, \& Prinz, 1998). They showed that directing the participants' attention toward the motion of the platform resulted in superior learning compared to directing attention toward the motion of the feet (Interestingly, learning was also enhanced relative to participants that received no instructions and could direct attention wherever they wanted, i.e., discovery learners). It is thought that an external focus enhances automaticity of motor performance (e.g., Kal, van der Kamp, \& Houdijk, 2013). There is debate, however, as to whether learning with an external focus of attention actually induces implicit learning. Poolton, Maxwell, Masters and Raab (2006), for example, showed that although the external focus resulted in significantly less declarative knowledge than an internal focus of attention (which is 
van der Kamp, J., Duivenvoorden, J. Kok, M, \& Van Hilvoorde, I. (2015). Motor skill learning in groups: Some proposals for applying implicit learning and self-controlled feedback. RICYDE. Revista internacional de ciencias del deporte, 39(11), 33-47. http://dx.doi.org/10.5232/ricyde2015.03903

equivalent to explicit learning), the amount of rules and facts accrued was still considerable. This raises the issue if an external focus genuinely induces implicit learning.

\section{A hurdle for implicit motor learning in groups}

Considering motor learning in groups, it is pertinent to recognize that the methods for implicit motor learning are typically validated for individual learning; participants practice on their own with only the researcher present. However, the dynamics of motor learning in groups, certainly in groups of school children, are crucially different. MacPhail, Kirk and Griffin (2008) observed that learning to catch and to throw balls in physical education lessons is not strictly individual, but normally involves interactions with classmates. When throwing and catching balls, children must adapt to each other's skills, and in the process are likely to instruct each other, also on how motor performance can be improved. For example, Koekoek and Knoppers (2013) interviewed children after a physical education lesson in which they played a baseball game. They quote a girl saying that "[Hitting the ball improves] when I ask other children how I must hold the bat" (p. 11). This is only one example, and in a slightly different context than motor skill learning per se, but it may well be the rule of what happens during physical education, rather than the exception. Obviously, children also watch classmates. In fact, observation has been demonstrated to be an effective means for motor skill learning, also in children. And although a recent meta-analysis (Ashford, Davids, \& Bennett, 2009) suggests that in children observation particularly triggers learning about the desired outcome of a skill, this certainly does not rule out that children can also learn about how the motor skill is best performed from watching others. In short, the interactions among children in a classroom may easily result in a focus on movement execution. It is impossible (and pedagogically undesirable, we would add) for the teacher to control all of the children's talking, watching and thinking, including deliberations of how they should move or seek ways to improve performance. With regards to implicit learning, however, this implies that a teacher needs to take additional measures to stop children from building a large pool of declarative knowledge. What methods of implicit motor learning do physical education teachers have available, and is implicit learning in groups feasible at all?

\section{Implicit motor learning in groups: Some proposals}

Except for two notable exceptions (Capio et al., 2012, 2013, see below), we do not know of any other research that directly addressed or tested the feasibility for implicit motor learning in physical education or other group settings. The examples that we discuss in this section, most of which were taken from conversations with educators and coaches, should therefore be taken as tentative proposals that may be valuable -we think- for teachers or coaches to consider implementing in their lessons, and for researchers to assess to what degree they indeed enable implicit motor learning.

The common characteristic in these proposals for implicit learning in groups is to try to prevent the learners from becoming (overly) aware of their movements. The classical way to achieve this is by using a concurrent secondary task -at least in research (e.g., Masters, 1992). A secondary task tends to overload working memory, and thus reduces the amount of declarative knowledge about the motor skill that will be accumulated. Yet, the secondary tasks used in research are not in any way related to the to-be-learned motor skill (e.g., random letter generation, tone counting etc.) and are likely to be demotivating, particularly for children. Therefore, the challenge for the teacher or coach is to design exercises that do load working memory, but are closely related to the motor activity. The Teaching Games for Understanding (TGfU) approach may offer such a method. By using small-sided games, TGfU intends to further children's tactical awareness of a game, with improvements in motor 
skill being only of secondary importance. Yet, TGfU can also be exploited with an eye for developing the children's motor skill implicitly. In fact, from its inception it has been argued that in TGfU the game situations unwittingly elicit improvements of motor skill as well (Bunker \& Thorpe, 1982; see also Koekoek \& Knoppers, 2013; Tan, Chow \& David, 2012), although this contention still seems to need careful scrutiny. In TGfU, dynamic games with a complex set of rules are downsized in such manner that the learners' attention is more easily exposed to those tactical aspects of the game the teacher wants them to acquire. Typically, this is done by reducing the amount of players or the size of the playing field or by altering equipment or target sizes. The TGfU approach has been shown to result in more declarative knowledge about game tactics and better decision making skills in sports like soccer and volleyball (e.g., Mitchell, Griffin, \& Oslin, 1995; Vande Broek, Boen, Claessens, Feys, \& Cuex, 2011). Yet, except for the tactical aspects, also motor skills may improve, although this has not been examined in much detail (cf., Mitchell et al., 1995). For example, Tan et al. (2012) propose to use long and narrow courts for net games that encourage learners to direct shots to the front and back. This increases children's awareness of hitting the ball in space (Note that within the TGfU approach children are challenged to obtain tactical knowledge by self-discovery rather than by teacher instruction, thus leading to declarative knowledge about tactics). However, besides the deliberate emphasis on the (tactical) role of overhead clear and drop shot during play, it is also likely to advance the execution of these strokes without children consciously attending to it (Renshaw, Chow, Davids, \& Hammond, 2010). Another example is small-sided invasion games, like soccer or field hockey, with four offensive players and three defensive players and a keeper (rather than the whole team) in a small field. By modifying the rules of the game (e.g., the number of consecutive passes or interceptions scores more points than a goal) passing and interception skills can be promoted implicitly. Not only because children will attempt more passes and interception than in regular games, but also because the strict time constraints enforce enhanced speed of action (see Davids, Button, \& Bennet, 2008; Koekoek, Dokman \& Wallinga, 2011).

To summarize, the TGfU approach allows a teacher to deliberately direct the attention of a group of children to learning to make correct tactical decisions and, at the same time, have children practice their motor skills. The teacher, however, does not explicitly address the latter, and in this way can enable motor skill learning implicitly. Nonetheless, if a teacher perceives the need to intervene in children's motor skill learning process, they best do so by directing attention toward the more global aspects of the movement (i.e., analogy learning) or toward the effects of the movement in the immediate environment (i.e., learning with an external focus of attention) (see Table 1). 
van der Kamp, J., Duivenvoorden, J. Kok, M, \& Van Hilvoorde, I. (2015). Motor skill learning in groups: Some proposals for applying implicit learning and self-controlled feedback. RICYDE. Revista internacional de ciencias del deporte, 39(11), 33-47. http://dx.doi.org/10.5232/ricyde2015.03903

\begin{tabular}{|c|c|c|}
\hline Strategy & Method & Activities \\
\hline \multirow[t]{3}{*}{$\begin{array}{l}\text { Circumventing } \\
\text { working memory }\end{array}$} & TGfU & $\begin{array}{l}\text { - Small-sided invasion games to emphasize tactical skills in } \\
\text { football, field hockey etc. Attention is directed to game tactics } \\
\text { and/or collaboration with teammates rather than motor skills. } \\
\text { - Changing the rules, fields of a game. E.g., the rule 'only one } \\
\text { moment of ball contact is allowed' directs attention to teammates } \\
\text { and prevents children from focussingon movement execution. It } \\
\text { is likely to increase speed of action. }\end{array}$ \\
\hline & $\begin{array}{l}\text { External focus of } \\
\text { attention }\end{array}$ & $\begin{array}{l}\text { - Games in javelin throw, short put etc. Attention is directed to the } \\
\text { landing area by games like 'four in a row'. }\end{array}$ \\
\hline & & $\begin{array}{l}\text { - The use of games in swimming to teach children to be safe and } \\
\text { move efficiently in the water. Without motor skill instructions, } \\
\text { children focus on movement outcomes that coincide with the } \\
\text { goals of the games. }\end{array}$ \\
\hline \multirow[t]{2}{*}{$\begin{array}{l}\text { Prevent } \\
\text { hypothesis } \\
\text { testing }\end{array}$} & Errorless learning & $\begin{array}{l}\text { - Practicing motor skills by making the task gradually more } \\
\text { difficult. For instance, by initially using a low basket or net or a } \\
\text { large goal, but slowly adjust to regular measures. } \\
\text { - Javelin throwing, shot put etc. can be practiced using landing } \\
\text { areas at a gradually increasing distance or decreasing size. }\end{array}$ \\
\hline & $\begin{array}{l}\text { Altering } \\
\text { environmental } \\
\text { and task } \\
\text { constraints }\end{array}$ & $\begin{array}{l}\text { - Motor skills (or movement patterns) are dictated by the } \\
\text { environment; that is, different environments or implements } \\
\text { demand different motor solutions. E.g., using light or heavy balls, } \\
\text { small-sized rackqets, or net height in tennis. }\end{array}$ \\
\hline $\begin{array}{l}\text { Global } \\
\text { instructions }\end{array}$ & Analogy learning & $\begin{array}{l}\text { - In javelin throwing, the 'proud waiter in a busy restaurant' to } \\
\text { hold the javelin high, stand upright using an upward grip aligned } \\
\text { with the body. } \\
\text { - In softball 'hitting the ball as if they are sweeping the tableware } \\
\text { off the table'. }\end{array}$ \\
\hline
\end{tabular}

We do think, however, that there is a potential pitfall of these more prescriptive methods when utilized in groups, particularly when they are used in isolation; children's intention (i.e., to be distinguished from attention!) is easily shifted toward improving the motor performance. Besides that some have argued that implicit learning can only come about without the intention to improve (e.g., Reber, 1992), in groups the goal of improving motor skills may lead children to more quickly turn to each other to seeks ways to perform better. Arguably counterintuitive, but it cannot be ruled out that given the classroom group interactions, implicit motor learning may be better enabled when children do not primarily aim for increasing motor skill.

Error-minimizing learning is the only method for implicit motor learning that has been validated in groups. Capio and colleagues $(2012,2013)$ practiced 8 - to 12 -year old children's fundamental movement skill of throwing in groups in three 15-min. sessions during physical education lessons over a three-week period (40 practice throws in each session). Children learned to throw beanbags towards a target at a distance of $5 \mathrm{~m}$. They practiced in pairs. To induce implicit motor learning, children started with a large target $(2.4 \times 2.4 \mathrm{~m})$ that was reduced to smaller size in the second $(1.1 \times 1.1 \mathrm{~m})$ and third practice sessions $(0.45 \times 0.45$ $\mathrm{m})$. This gradual decrement in target size minimized the amount of errors compared to practicing with a progressively larger target. Importantly, the error-minimizing protocol not only resulted in greater gains in throwing accuracy and movement form, but also in more 
effective throwing with a concurrent secondary task (i.e., counting backwards). In other words, error-minimizing learning resulted in throwing performance that was less reliant on working memory involvement, suggesting that the children had learnt implicitly (see also Capio et al., 2012). Especially children with poor throwing skills benefitted from this approach, thereby underlining its value as a means to induce implicit motor learning in educational settings at primary schools. As a concluding thought, error-minimizing learning is easily unified with the constraints-led approach (Davids et al., 2008; Renshaw et al., 2010). In this approach, the environment and/or task are modified to channel the acquisition of motor skills. For instance, children play tennis with lowered nets or smaller racquets, or the rules of a game are modified as in the TGfU approach. The role of the teacher is to identify and manipulate the key constraints to facilitate the emergence of functionally appropriate movement patterns (Renshaw et al., 2010, p. 120). The teacher's challenge is to modify the environment or task in such a way that it is tailor-made for the individual child. This is not always straightforward. On the one hand, a task that is too easy will not advance a child's motor skill, while on the other hand, a task that is too demanding will induce many errors and make a child more prone to deliberately search for ways to improve performance. Typically, motor skills differ considerably among children of the same year, and consequently, a teacher may have to differentiate in small groups of children.

\section{Self-controlled feedback}

We now turn to self-controlled feedback, a learning method that stands diametrically opposed to implicit motor learning. Like other forms of augmented feedback, self-controlled feedback aims to raise a learner's awareness of how a motor skill can be performed best -presumably increasing the learner's pool of declarative knowledge- but leaves the decision of when to receive feedback to the learner. This differs from traditional approaches, in which a researcher (or a teacher) establishes the practice conditions by choosing practice exercises, practice materials, but also the types of instruction and feedback, including their frequency and scheduling. With self-controlled feedback, however, a learner becomes more actively involved in his or her own learning process, which in itself is an important objective of physical education (Brouwer et al., 2012; Hellison, 1984). We first briefly review the recent literature that shows the benefits of self-controlled feedback for motor skill learning and selfefficacy in children, and then discuss its applicability for motor skill learning in groups.

\section{Self-controlled and externally-controlled feedback}

In the vast majority of motor skill learning the frequency and scheduling of feedback is externally controlled. The researcher determines when and what feedback is provided to the participant. By contrast, in self-controlled feedback, a learner decides after each practice attempt whether or not she or he wants to receive feedback. To assess the effects of selfcontrol on motor skill learning, performance of a self-controlled feedback group is usually compared to a so-called yoked group. Each of the participants in the yoked group is matched to a participant in the self-control group. Each time the participants in the self-controlled feedback group request feedback, their counterparts in the yoked group also receive feedback. Hence, the feedback schedule of the two groups is identical; the only difference being that the self-controlled feedback group is in charge over its feedback schedule, while the feedback schedule of the yoked group is externally controlled.

Adopting this design, Janelle, Barba, Frehlich, Tennant and Cauraugh (1997) had participants practice throwing a tennis ball with their non-dominant hand to a target at 9-meter distance. Video replay of the last two pitches along with verbal cueing of the most critical error served as feedback. Participants in the self-controlled feedback group showed improved throwing 
van der Kamp, J., Duivenvoorden, J. Kok, M, \& Van Hilvoorde, I. (2015). Motor skill learning in groups: Some proposals for applying implicit learning and self-controlled feedback. RICYDE. Revista internacional de ciencias del deporte, 39(11), 33-47. http://dx.doi.org/10.5232/ricyde2015.03903

accuracy and movement form compared to participants in the yoked group. These benefits of self-controlled feedback in adults' motor skill learning have been confirmed by several research groups for both knowledge of performance and knowledge of results feedback (e.g., Aiken, Fairbrother, \& Post, 2012; Chiaviacowksi \& Wulf, 2002).

Yet, for children, whose executive functions such as working memory are not fully developed (Gathercole \& Alloway, 2008), the decision for requesting feedback may be overwhelming and potentially hindering motor skill learning. Nevertheless, Chiviacowski, Laroque de Medeiros, Kaefer, and Tani (2008) found that 10-year-old children outperformed their yoked peers after self-controlled feedback (i.e., knowledge of results) when learning to toss a beanbag with the non-dominant arm towards a target with a blindfold. Ste-Marie, Vertes, Law and Rymal (2013) found similar advantages of self-controlled feedback in 11-year-olds learning progressively difficult trampoline skills, a task which is much more representative for physical education. If they wished, children watched video recordings of their own jumps (knowledge of performance) with a researcher verbally cueing critical execution errors (e.g., 'focus on where your arms are') and providing instructions how to overcome these errors in the next jump. The children with self-controlled feedback not only progressed further, but also showed greater positive changes in self-efficacy during acquisition (which however did not sustain during retention) and in perceived success and motivation than children with externally-controlled feedback. In fact, Ste-Marie and colleagues (2013) have argued that the advantages of self-control stem from these increases in self-efficacy and motivation, which may induce more elaborate processing of the information provided in the feedback. Finally, and as an aside, studies with both adults and children indicate that increased self-efficacy and motor skill learning with self-controlled feedback is related to learners predominantly asking feedback after successful rather than unsuccessful attempts (Chiviacowski \& Wulf, 2002; Chiviacowski \& Wulf, 2007; Fairbrother, Laughlin \& Nguyen, 2012; see also Saemi, Porter, Ghotbi-Varzaneh, Zargami \& Maleki, 2012). This is not only of relevance to teachers and trainers, but also questions the widely accepted claim that feedback functions to correct errors (Salmoni, Schmidt, \& Walter, 1984).

\section{A hurdle for self-controlled feedback in groups}

The positive effects attributed to self-controlled feedback on motor skill learning, selfefficacy and motivation are of high practical relevance. However, similar to studies on implicit motor learning, the experimental work showing the advantages of self-controlled feedback typically involve individual learning; the experimenter provides feedback after the individual participant requests it. There is only the interaction between a single participant and the researcher. In settings such as physical education involving 20 to 30 children, however, it is simply not feasible for the teacher to provide individual feedback to all children separately the moment they ask for it. The use of video feedback does not ameliorate this problem, because video feedback is only effective with additional attentional cueing, particularly in children (for a overviews, see Hodges \& Ste-Marie, 2013; Ste-Marie, Law, Ryma, Hall, \& McCullagh, 2012). In addition, it appears that children that request feedback more often than their peers demonstrate enhanced learning (Chiviacowski, Wulf, Laroque de Medeiros, Kaefer, \& Wally, 2008). And whereas adults tend to ask for feedback relatively infrequently, after a little more than $10 \%$ of the attempts (Janelle et al., 1997), children are reported to ask after one-third of the trials or more frequently (e.g., Chiviacowski et al. 2008; Ste-Marie et al., 2013). Clearly, it is impossible for a teacher to meet this need for feedback and additional attentional cueing with a group of over 20 children. This raises the issue to what degree self-controlled feedback can be implemented in physical education settings, and if so, whether the acclaimed advantages will still hold. 


\section{Self-controlled feedback in groups: Some proposals}

Notwithstanding the practical issues, there may be a few possibilities to implement selfcontrolled feedback during physical education classes. Again, currently these are unverified proposals only. The basic strategy would be to rely on sources other than the teacher to provide the feedback and/or the extra attentional cueing. For example, classmates can be involved in providing feedback. The teacher can form small groups, in which children give feedback to their classmates when requested. In fact, by using the now ubiquitous smartphones or tablets, children can record each other's practice attempts and look back and discuss the strengths and weaknesses. Yet, although this may be promising for developing social skills, it remains to be seen whether the feedback content is of sufficient quality to enhance motor skill, not the least because the children may struggle to identify the strong and weak points in their classmates' performances. Possibly, the feedback content can be elevated by supplementing the children's recordings with an (expert) model. Video analysis and sport Apps like Coach's Eye or Ubersense have split-screen functions that allow a side-by-side comparison of the children's recordings with the model. At the start of practice, the teacher can instruct about the points of interest. Most video analysis Apps include drawing tools that can help call out the points of interests in the model's action.

These tools are currently readily available, but it is unclear whether or not they actually suffice in guiding children's attention (or adults' attention for that matter). Yet, in due course we envision at least one further development. This revolves around introducing a more encompassing method to guide a learner's attention toward points of interest of the actions of the model. A case in point is the eye movement modelling examples (EMME's; Jarodzka, Scheiter, Gerjets \& van Gog, 2010; Jarodzka, van Gog, Dorr, Scheiter \& Gerjets, 2013), which is developed for self-controlled learning for subjects like mathematics, biology, chemistry and so on. With EMME, the displayed actions of the model are overlaid with a highlight that reflects the teacher's spatio-temporal gaze pattern watching the model. Importantly, the teacher's gaze pattern is recorded while she or he instructs on the points of interest for identifying or imitating the model's action when she or he watches the model heror himself. Namely, a teacher's gaze pattern is typically strongly correlated to her or his verbal instructions (Jarodzka et al., 2010). The resulting video of the model includes both a highlight of the teacher's eye movements and an audio with the accompanying instructions and attentional cueing. In this regard, Jarodzka and colleagues $(2010,2013)$ taught students to classify patterns of locomotion in fish with the use of EMME, which involved video recordings of swimming fish with the instructor's eye movements superimposed on it together with the verbal instructions. Compared to students that watched the video with verbal instructions only, the EMME significantly increased learning. Similar effects have been found in adult goalkeepers learning to save a penalty kick (Savelsbergh, van Gastel \& van Kampen, 2010; Ryu, Kim, Abernethy, \& Mann, 2012). Clearly, we need research that corroborates the benefits of EMME in motor skill learning with self-controlled feedback in children. And if confirmed, we may still have to wait for laptops or tablets with eye movement recording devices to become commercially available for the physical education teacher.

\section{Conclusion}


Recent years have seen a surge in studies examining new methods for teaching motor skill learning. Amongst other things, implicit learning and self-controlled feedback have been proposed to accelerate motor skill learning and to increase the learner's self-efficacy, although the empirical support for the latter contention is still weak. Importantly, however, the vast majority of this research is based on individual learning: it involves researchers interacting with a single participant at the time. By contrast, most of the institutional settings for motor skill learning, especially for children, involve teachers or coaches working with groups of learners. Even though there is very little research on the issue, it seems feasible to implement methods to promote implicit learning and self-controlled feedback for groups of children. As a final thought, however, we do note that implicit learning and self-controlled feedback do place very different demands on children. Working memory, for instance, is likely to have a fundamentally different impact on the two methods. And with the large differences in working memory (or more generally executive function) among children (Gathercole \& Alloway, 2008), a next step would perhaps be to address issues of differentiation of methods of motor learning within groups of children not only in relation to motor ability but also in terms of executive functions (see e.g. Buszard, Farrow, Reid \& Masters, 2014).

\section{References}

Aiken, C. A.; Fairbrother, J. T.; Post, P. G (2012). The effects of self-controlled video feedback on the learning of a basketball set shot. Frontiers in psychology, 3, 338. http://dx.doi.org/10.3389/fpsyg.2012.00338

Anderson, J. R. (1982). Acquisition of cognitive skill. Psychological Review, 89, 369-406. http://dx.doi.org/10.1037/0033-295X.89.4.369

Ashford, D.; Davids, K., \& Bennett, S.J. (2009). Developmental effects influencing observational modelling: A meta-analysis. Journal of Sports Sciences, 25, 547-558. http://dx.doi.org/10.1080/02640410600947025

Berry, D.C., \& Broadbent, D.E. (1988). Interactive tasks and the implicit explicit distinction. British Journal of Psychology, 79, 251-272. http://dx.doi.org/10.1111/j.2044-8295.1988.tb02286.x

Brouwer, B.; Houthoff, D.; Massink, M.; Mooij, C.; Mossel van, G.; Swinkels, E. (2012). Basisdocument: bewegingsonderwijs voor de onderbouw van het voortgezet onderwijs. Zeist: Jan Luiting Fonds.

Buszard, T.; Farrow, D.; Reid, M., \& Masters, R.S.W. (2014). Scaling sporting equipment for children promotes implicit processes during performance. Consciousness \& Cognition (in press).

Bunker, D., \& Thorpe, R. (1982). A model for the teaching of games in secondary schools. Bulletin of Physical Education 18, 5-8.

Capio, C.M.; Poolton, J.M.; Sit, C.H.P.; Eguia, K.F., \& Masters, R.S.W. (2012) Reduction of errors during practice facilitates fundamental movement skill learning in children with intellectual disabilities. Journal of Intellectual Disability Research, 57, 295-305. http://dx.doi.org/10.1111/j.1365-2788.2012.01535.x

Capio, C.M.; Poolton, J.M.; Sit, C.H.P.; Holmstrom, M., \& Masters, R.S.W. (2013). Reducing errors benefits the field-based learning of a fundamental movement skill in children. Scandinavian Journal of Medicine \& Science in Sport, 23, 181-188. http://dx.doi.org/10.1111/j.1600-0838.2011.01368.x

Chiviacowski, S., \& Wulf, G. (2002). Self-controlled feedback: does it enhance learning because performers get feedback when they need it? Research Quarterly for Exercise 
van der Kamp, J., Duivenvoorden, J. Kok, M, \& Van Hilvoorde, I. (2015). Motor skill learning in groups: Some proposals for applying implicit learning and self-controlled feedback. RICYDE. Revista internacional de ciencias del deporte, 39(11), 33-47. http://dx.doi.org/10.5232/ricyde2015.03903

and Sport, 73, 408-415.

http://dx.doi.org/10.1080/02701367.2002.10609040

Chiviacowski, S., Wulf, G. (2007). Feedback after good trials enhances learning.

Research Quarterly for Exercise and Sport, 78, 40-47.

http://dx.doi.org/10.1080/02701367.2007.10599402

Chiviacowski, S.; Wulf, G.; Laroque de Medeiros, F.; Kaefer, A., \& Tani, G. (2008). Learning benefits of self-controlled knowledge of results in 10-year-old children. Research Quarterly for Exercise and Sport, 79, 405-410. http://dx.doi.org/10.1080/02701367.2008.10599505

Chiviacowski, S.; Wulf, G.; Laroque de Medeiros, F.; Kaefer, A., \& Wally R. (2008). Selfcontrolled feedback in 10-year-old children: higher feedback frequencies enhance learning. Research Quarterly for Exercise and Sport, 79, 122-127.

Davids, K.; Button, C., \& Bennett, S. (2008). Dynamics of skill acquisition in sport: Constraints-led approach. Champaign, IL: Human Kinetics.

Fairbrother, J.T.; Laughlin, D.D., \& Nguyen, T.V. (2012). Self-controlled feedback facilitates motor learning in both high and low activity individuals. Frontiers in Psychology, 3, 323.

http://dx.doi.org/10.3389/fpsyg.2012.00323

Fitts, P.M., \& Posner, M.I. (1967). Human Performance. Belmont, CA: Brooks/Cole.

Gathercole, S. E., \& Alloway, T. P. (2008). Working memory and learning: A practical guide. Sage Press.

Hardy, L.; Mullen, R., \& Jones, G. (1996). Knowledge and conscious control of motor actions under stress. British Journal of Psychology, 87, 621-636. http://dx.doi.org/10.1111/j.2044-8295.1996.tb02612.x

Harter, S. (1978) Effectance motivation reconsidered: Toward a developmental model. Human Development, 21, 34-64.

http://dx.doi.org/10.1159/000271574

Hellison, D.R. (1984). Goals and strategies for teaching physical education. Champaign, IL: Human Kinetics Publishers.

Hodges, N.J., \& Ste-Marie, D. (2013). Observation as an instructional method. In: D. Farrow, J. Baker, \& C. MacMahon, (Eds.), Developing sport expertise: researchers and coaches put theory into practice 2nd Edition (pp. 115-128). New York, NY: Routledge

Janascek, K., \& Nemeth, D (2013). Implicit sequence learning and working memory: Correlated or complicated? Cortex, 49, 2001-2006. http://dx.doi.org/10.1016/j.cortex.2013.02.012

Janelle, C.M.; Barba, D.B.; Frehlich, S.G.; Tennant, L.K., \& Cauraugh, J.H. (1997). Maximizing performance feedback effectiveness through videotape replay and a selfcontrolled learning environment. Research Quarterly for Exercise and Sport, 68, 269279. http://dx.doi.org/10.1080/02701367.1997.10608008

Jarodzka, H.; Scheiter, K.; Gerjets, P., \& van Gog, T. (2010). In the eyes of the beholder: How experts and novices interpret dynamic stimuli. Learning and Instruction, 20, 146-154.

http://dx.doi.org/10.1016/j.learninstruc.2009.02.019

Jarodzka, H.; van Gog, T.; Dorr, M. Scheiter, K., \& Gerjets, P. (2013). Learning to see: Guiding students' attention via a Model's eye movements fosters. Learning and 
van der Kamp, J., Duivenvoorden, J. Kok, M, \& Van Hilvoorde, I. (2015). Motor skill learning in groups: Some proposals for applying implicit learning and self-controlled feedback. RICYDE. Revista internacional de ciencias del deporte, 39(11), 33-47. http://dx.doi.org/10.5232/ricyde2015.03903

Instruction, 25, 62-70.

http://dx.doi.org/10.1016/j.learninstruc.2012.11.004

Kal, E.C.; van der Kamp, J., \& Houdijk, H. (2013). External attentional focus enhances movement automatization: A comprehensive test of the constrained action hypothesis. Human Movement Sciences, 32, 527-539. http://dx.doi.org/10.1016/j.humov.2013.04.001

Koekoek, J.; Dokman, I., \& Wallinga, W. (2011). Sportspelen. Den Haag: Boom Lemma Uitgevers.

Kleynen, M.; Braun, S.M.; Bleijlevens, M.H.; Lexis, M.A.; Rasquin, S.M.; Halfens, J.; Wilson, M.R.; Beurskens, A.J., \& Masters, R.S.W. (2014). Using a Delphi technique to seek consensus regarding definitions, descriptions and classification of terms related to implicit and explicit forms of motor learning. PLoS ONE, 9(6), e100227. http://dx.doi.org/10.1371/journal.pone.0100227

Koekoek, J., \& Knoppers, A. (2013). The role of perceptions of friendships and peers in learning skills in physical education. Physical Education and Sport Pedagogy (in press). http://dx.doi.org/10.1080/17408989.2013.837432

Lam, W.K.; Maxwell, J.P., \& Masters, R.S.W. (2009). Analogy versus explicit learning of a modified basketball shooting task: Performance and kinematic outcomes. Journal of Sports Sciences, 27, 179-191. http://dx.doi.org/10.1080/02640410802448764

Liao C.M., \& Masters, R.S.W. (2001). Analogy learning: A means to implicit motor learning. Journal of Sports Sciences, 19, 307-319. http://dx.doi.org/10.1080/02640410152006081

MacPhail, A.; Kirk, D., \& Griffin. L. (2008). Throwing and catching as relational skills in game play: Situated learning in a modified game unit. Journal of Teaching in Physical Education, 27, 100-115.

Masters, R.S.W. (1992). Knowledge, knerves and know-how: The role of explicit versus implicit knowledge in the breakdown of a complex motor skill under pressure. British Journal of Psychology, 83, 343-358. http://dx.doi.org/10.1111/j.2044-8295.1992.tb02446.x

Masters, R.S.W.; Lo, C.Y.; Maxwell, J.P., \& Patil, N.G. (2008). Implicit motor learning in surgery: Implications for multi-tasking. Surgery, 143, 140-145. http://dx.doi.org/10.1016/j.surg.2007.06.018

Masters, R.S.W., \& Poolton, J. (2012). Advances in implicit motor learning. In N.J. Hodges \& A.M. Williams (Eds.), Skill Acquisition in Sport: Research, Theory and Practice (2nd ed.) (pp. 59-75). London: Routledge.

Masters, R.S.W.; Poolton, J.M., \& Maxwell, J.P. (2008). Stable implicit motor processes despite aerobic locomotor fatigue. Consciousness and Cognition, 17, 335-338. http://dx.doi.org/10.1016/j.concog.2007.03.009

Masters, R.S.W.; van der Kamp, J., \& Capio, C. (2013). Implicit motor learning by children. In J. Côté \& R. Lidor (Eds.), Conditions of children's talent development in sport (pp. 21-40). West Virginia: Fitness Information Technology.

Maxwell J.P.; Masters, R.S.W.; Kerr, E., \& Weedon, E. (2001) The implicit benefit of learning without errors. The Quarterly Journal of Experimental Psychology Section A, 54, 1049-1068.

http://dx.doi.org/10.1080/713756014 
van der Kamp, J., Duivenvoorden, J. Kok, M, \& Van Hilvoorde, I. (2015). Motor skill learning in groups: Some proposals for applying implicit learning and self-controlled feedback. RICYDE. Revista internacional de ciencias del deporte, 39(11), 33-47. http://dx.doi.org/10.5232/ricyde2015.03903

Mitchell, S.A.; Griffin, L.L., \& Oslin, J.L. (1995). The effects of two instructional approaches on game performance. Pedagogy in Practice: Teaching and Coaching in Physical Education and Sports 1, 36-48.

Mullen, R.; Hardy, L., \& Oldham, A. (2007). Implicit and explicit control of motor actions: revisiting some early evidence. British Journal of Psychology, 98, 141-156. http://dx.doi.org/10.1348/000712606X114336

Poolton, J.M.; Masters, R.S.W., \& Maxwell, J.P. (2007). Passing thoughts on the evolutionary stability of implicit motor behaviour: Performance retention under physiological fatigue. Consciousness and Cognition, 16, 456-468. http://dx.doi.org/10.1016/j.concog.2006.06.008

Poolton, J.M.; Maxwell, J.P.; Masters, R.S.W., \& Raab, M. (2006). Benefits of an external focus of attention: Common coding or conscious processing? Journal of Sport Sciences, 24, 89-99. http://dx.doi.org/10.1080/02640410500130854

Reber, A.S. (1992). An evolutionary context for the cognitive unconscious. Philosophical Psychology, 5, 33-51. http://dx.doi.org/10.1080/09515089208573042

Renshaw, I.; Chow, J.Y.; Davids, K., \& Hammond, J. (2010). A constraints-led perspective to understanding skill acquisition and game play: A basis for integration of motor learning theory and physical education praxis? Physical Education and Sport Pedagogy, 15, 117-137. http://dx.doi.org/10.1080/17408980902791586

Ryu, D.; Kim, S.; Abernethy, B., \& Mann, D.L. (2013). Guiding attention aids the acquisition of anticipatory skill in novice soccer goalkeepers. Research Quarterly for Exercise \& Sport, 84, 252-262. http://dx.doi.org/10.1080/02701367.2013.784843

Salmoni, A.W.; Schmidt, R.A., \& Walter, C.B. (1984). Knowledge of results and motor learning: A review and critical reappraisal. Psychological Bulletin, 95, 355-386. http://dx.doi.org/10.1037/0033-2909.95.3.355

Saemi, E.; Porter, J.M.; Ghotbi-Varzaneh, A.; Zarghami, M., \& Maleki, F. (2012). Knowledge of results after relatively good trials enhances self-efficacy and motor learning. Psychology of Sport and Exercise, 13, 378-382. http://dx.doi.org/10.1016/j.psychsport.2011.12.008

Savelsbergh, G.J.P.; Gastel, P.J. van, \& Kampen, P.M. van (2010). Anticipation of penalty kick direction can be improved by directing attention through perceptual learning. International Journal of Sport Psychology, 41, 24-41.

Ste-Marie, D.M.; Law, B.; Rymal, A.M.; O, J., \& Hall, C., \& McCullagh, P. (2012). Observation interventions for motor skill learning and performance: an applied model for the use of observation. International Review of Sport and Exercise Psychology, 121.

Ste-Marie, D.M.; Vertes, K.A.; Law, B., \& Rymal, A.M (2013). Learner-controlled selfobservation is advantageous for motor skill acquisition. Frontiers in Psychology, 3, 556. http://dx.doi.org/10.3389/fpsyg.2012.00556

Steenbergen, B.; van der Kamp, J.; Verneau, M.; Jongbloed-Pereboom, M., \& Masters, R.S.W. (2010). Implicit and explicit learning: Applications from basic research to sports for individuals with impaired movement dynamics. Disability and Rehabilitation, 32, 1509-1516.

http://dx.doi.org/10.3109/09638288.2010.497035 
van der Kamp, J., Duivenvoorden, J. Kok, M, \& Van Hilvoorde, I. (2015). Motor skill learning in groups: Some proposals for applying implicit learning and self-controlled feedback. RICYDE. Revista internacional de ciencias del deporte, 39(11), 33-47. http://dx.doi.org/10.5232/ricyde2015.03903

Tan, C.W.K.; Chow, J.Y., \& Davids, K. (2012). 'How does TGfU work?': Examining the relationship between learning design in TGfU and a nonlinear pedagogy. Physical Education and Sport Pedagogy, 17, 331-348. http://dx.doi.org/10.1080/17408989.2011.582486

Vande Broek, G.; Boen, F.; Claessens, M.; Feys, J., \& Ceuz, T. (2011). Comparison of three instructional approaches to enhance tactical knowledge in volleyball among university students. Journal of Teaching in Physical Education, 30, 375-392

Wulf, G.; Höß, M., \& Prinz, W. (1998). Instructions for motor learning: differential effects of internal versus external focus of attention. Journal of Motor Behavior, 30, 169179.

http://dx.doi.org/10.1080/00222899809601334 